\title{
El cultivo de la convivencia: una oportunidad para prevenir situaciones de acoso escolar*
}

\author{
The nurturing of coexistence: An opportunity to prevent school bullying \\ Adriana María Gallego ${ }^{(0)}$, José Federico Agudelo ${ }^{2}{ }^{(}$, Olga Cecilia Vásquez $^{3}$, \\ María Camila Restrepo ${ }^{4}$, Andrea Gálvez ${ }^{5}$
}

Para citar este artículo: Gallego, A. M., Agudelo, J. F., Vás-

Recibido: 01-11-2018 - Aceptado: 04-07-2019

quez, O. C., Restrepo, M. C., Gálvez, A. (2019). El cultivo

de la convivencia: una oportunidad para prevenir situacio-

nes de acoso escolar. Infancias Imágenes, 18(2). [159-170]

\section{Resumen}

El presente artículo de revisión tiene como objetivo generar reflexión sobre la importancia de la democracia y la convivencia en el aula de clase para intervenir y mitigar el acoso escolar. La metodología se basó en el estudio documental. Los resultados apuntan a que los maestros reconozcan los antecedentes legales sobre el acoso escolar, esto como posibilidad para intervenir desde la normativa estas situaciones. Se concluye que la familia tiene un papel importante frente a la formación de actitudes empáticas y competencias relacionadas con la tolerancia, la democracia y el respeto por la diversidad.

\begin{abstract}
Albstract
This study promotes the importance of democracy and coexistence in classrooms for the purpose of intermediation and alleviation of school bullying. The methodology was based on the desktop study. The results suggest that teachers should identify any legal antecedents regarding bullying because it may be possible to intervene through the legal system in such situations. It is concluded that family plays a major role in formation of empathic attitudes and skills related to tolerance, democracy and respect for diversity. Keywords: peaceful coexistence, democracy, teacher, violence
\end{abstract}

Palabras clave: convivencia pacífica, democracia, maestro, violencia.

* Este artículo de revisión es un producto derivado del proyecto de investigación "Del bullying y otras manifestaciones de inequidad en la escuela, una oportunidad para la formación de licenciados". Cuya fecha de inicio se dio en febrero de 2016 y fecha de finalización de actividades es noviembre de 2016. Este proyecto fue financiado por Universidad Católica Luis Amigó. La publicación será vinculada al grupo de investigación Educación, Infancia y Lenguas Extranjeras.

1 Magíster en Educación y Desarrollo Humano, Universidad de Manizales. Especialista en Docencia Investigativa Universitaria y Licenciada en Educación Preescolar, Universidad Católica Luis Amigó. Coordinadora de la Maestría en Educación y docente investigadora de la Facultad de Educación. Correo electrónico: adriana.gallegohe@amigo.edu.co

2 Magíster en Educación, Universidad Católica de Manizales (Manizales, Colombia). Licenciado en Filosofía, Universidad de Antioquia. Docente investigador, Universidad Católica Luis Amigó. Correo electrónico: jose.agudeloto@amigo.edu.co

3 Estudiante del Doctorado en Ciencias de la Educación, Universidad Nacional de Rosario, Argentina. Magíster en Educación y Desarrollo Humano, Universidad de Manizales. Especialista en Docencia Investigativa Universitaria y Especialista en Gestión Educativa, Universidad Católica Luis Amigó. Licenciada en Educación Preescolar, Universidad San Buenaventura, Medellín. Socióloga, Universidad Pontificia Bolivariana. Decana de la Facultad de Educación y Humanidades de la Universidad Católica Luis Amigó. Correo electrónico: dec.educacion@ amigo.edu.co

4 Licenciada en Educación Preescolar, Universidad Católica Luis Amigó. Docente del Colegio Parroquial Nuestra Señora del Buen Consejo. Correo electrónico: maria.restrepoal@amigo.edu.co

5 Licenciada en Educación Preescolar, Universidad Católica Luis Amigó. Docente del Jardín Buen Comienzo Mamá Chila. Correo electrónico: andrea.galvezva@amigo.edu.co 


\section{Introducción}

Históricamente, la violencia "se ha insertado en la intimidad de la familia, la escuela y la sociedad, generando transformaciones en lo que se refiere a las dinámicas sociales, culturales, familiares y en las relaciones interpersonales" (Gallego, 2011, p. 300), lo que posiblemente indica que este fenómeno se ha empezado a naturalizar, convirtiéndose en un aspecto que se vive en la cotidianidad no solo de la familia sino también de la escuela; escenario en el que por lo general se exteriorizan las acciones que habitualmente se reprimen en casa y que se concreta con los pares, lo que afecta la dinámica escolar.

Ahora bien, no toda acción de agresividad presente en el contexto de aula y entre pares es acoso escolar; para que se dé en realidad este fenómeno tiene que cumplir con dos condiciones: que sea "repetitivo e intencional [desagradable o hiriente] de una o más personas" (Olweus, 1993, p. 2) a alguien que cree que no posee las condiciones para defenderse. En sintonía con lo dicho, Cerezo afirma que el acoso escolar es "una conducta oculta, especialmente para los adultos, y solo es conocida cuando la victimización es elevada" (2012, p. 25). La anterior afirmación se convierte en un aspecto preocupante porque lo que el autor está indicando es que este tipo de conductas en su fase inicial es ignorado por los adultos cuidadores denominándola en muchas ocasiones como "COsas de niños"; solo en su fase avanzada se toma en serio. En este sentido, es necesario generar una cultura de denuncia en el grupo de espectadores, lo que se puede convertir en clave para su intervención. El otro aspecto que subrayan los teóricos es que quien agrede se esconde de las figuras de autoridad con el fin de evitar ser sancionado; y el agredido se siente mutilado en su capacidad para tomar la decisión de denunciar a quién o quiénes hacen las veces de agresores.

Otro rasgo de este fenómeno son las diversas formas en que se materializa la conducta del acoso escolar; estas pueden ser: física, psicológica, verbal y cibernética. Examinaremos brevemente los tipos de acoso escolar con el fin de que el lector tenga una idea clara y diferenciada de cada uno.
Por ejemplo, para Domínguez y Manzo (2011), el maltrato escolar físico se caracteriza por acciones corporales dañinas, como empujones, golpes, patadas, entre otras; la intimidación verbal se reconoce por sus actos de discriminación, de exclusión y de rumores a través de la palabra, utilizando apodos, insultos o amenazas; el psicológico va desde miradas hasta gestos obscenos y desagradables con la intención de intimidar a la víctima; por último, el cibernético es la forma más nueva de acoso escolar, este procede de la globalización en la que los dispositivos electrónicos y los canales de comunicación como redes sociales son usados como medios para agredir a los demás. Asimismo, es importante señalar que en el ámbito escolar se evidencia principalmente la violencia verbal y la violencia psicológica (Arellano, Chirinos, López y Sánchez, 2007; Arellano, 2008), porque la intención es que la víctima pierda su autoestima, seguridad y capacidad para expresarse; en pocas palabras, la intención del victimario es reducir a la víctima.

Cada una de estas formas de violencia escolar "destruye lenta, pero profundamente, la autoestima y la confianza del escolar agredido, que puede llegar a estados depresivos o de permanente ansiedad [...], le hará más difícil su adaptación social y su rendimiento académico" (Avilés, 2002, p. 12) y para el agresor y los testigos, consecuencias como "el desensibilizarse ante el sufrimiento de otras personas y el reforzar el individualismo" (Trautmann, 2008, p. 15). Lo señalado hasta aquí indica que el fenómeno del acoso escolar trae consecuencias negativas para todos los actores (víctimas, victimarios o espectadores), en tanto que todos, de una u otra manera, salen perdiendo.

El acoso escolar se manifiesta con una mayor preponderancia en espacios diferentes al aula de clase, por ejemplo, el patio, los pasillos y baños (Collel y Escudé, 2002) debido a que como son espacios abiertos y amplios la capacidad de control por parte de los profesores disminuye considerablemente. No obstante, cabe resaltar que los "victimarios" buscan esconderse de las miradas adultas para acechar a la víctima; sin embargo, parece que un rasgo psicológico del acoso escolar es la intención de que este se haga visible pero solo entre el grupo 
de cercanos y de confianza para que su acto de acoso tenga fiabilidad y lo empodere como líder.

Frente a este tipo de espacios donde se concretan las conductas de acoso se requiere que los maestros estén atentos a situaciones y comportamientos inusuales en tanto estos en el escenario escolar encarnan la norma y la autoridad; y son los llamados a estar preparados en términos académicos, legales y pedagógicos para encarar desde acciones de convivencia conductas que obstaculizan la vida de la institución educativa.

En Colombia se creó el Sistema Nacional de Convivencia Escolar con la Ley 1620 del 2013. Con esta normativa se busca la prevención y mitigación del acoso escolar, la formación para los derechos humanos y la educación para la sexualidad y la paz. Además, invita a la prevención de la violencia en la escuela para hacer de esta un lugar donde niños, niñas y jóvenes se formen como ciudadanos democráticos, aportando no solo a su crecimiento personal, sino al desarrollo de todo un país.

Con respecto a los planteamientos expuestos, con este texto se busca generar reflexión desde las categorías: papel del maestro, democracia y la convivencia en el aula de clase para intervenir y mitigar el acoso escolar. De este modo, el lector encontrará tres apartados. El primero titulado: Normativas legales sobre acoso escolar: conocimientos obligatorios para los maestros, en el que se presentan algunos antecedentes desde la normativa colombiana sobre convivencia y democracia; igualmente, las estrategias que la Ley 1620 aporta a los docentes y a las instituciones educativas con el fin de solucionar o intervenir conflictos que afecten la convivencia. En el segundo apartado, denominado La democracia: punto de partida para mejorar los procesos de convivencia en la escuela, se realiza un acercamiento teórico a la categoría de democracia y cómo esta permite que la comunidad educativa sea partícipe de los procesos que se tejen en la escuela día a día, consintiendo así que la convivencia escolar tenga significado para todos. En la tercera parte, Familia y escuela: instituciones responsables de cultivar la convivencia, se presenta la importancia de estos escenarios de socialización en cuanto a la formación de los individuos de una sociedad como constructores de paz.

\section{Método}

El presente artículo hace énfasis en la revisión documental, por lo cual se tomaron como puntos centrales las categorías: democracia y convivencia escolar. La búsqueda documental estuvo orientada a partir de las siguientes preguntas: ¿cuál es el papel del docente frente a las situaciones de violencia en la escuela?, ¿qué papel tienen la convivencia y la democracia en la escuela?, ¿el fenómeno del acoso escolar surge exclusivamente en los establecimientos educativos?

Posterior a esto, se inició la búsqueda de los textos, la cual se realizó en la plataforma de SCImago Journal \& Country Rank y en bases de datos en línea como Google Académico, Dialnet, Scielo, EBSCO y revistasen línea como la Revista Virtual Universidad Católica del Norte, Revista Internacional Magisterio, Revista Colombiana de Educación, Revista de Pedagogía, entre otras. También, se rastreó en bibliotecas de la ciudad de Medellín como la de la Universidad Católica Luis Amigó, la Universidad de Antioquia, la Universidad Pontificia Bolivariana y la Universidad Nacional de Colombia.

A partir de este rastreo se encontraron alrededor de 50 textos que respondían a las categorías ya mencionadas y que se relacionaban con los temas de convivencia escolar, acoso escolar, normativa, situaciones de violencia a nivel territorial, papel de la familia y del maestro y participación ciudadana en la escuela. A partir de los textos encontrados se realizó organización de la información en fichas de contenido. Posteriormente, se usaron matrices categoriales para clasificar y analizar la información por temas, donde surgieron las categorías emergentes: papel del docente, formación ciudadana, artículos y leyes. Finalmente, se procedió a la escritura de los siguientes resultados.

\section{Resultados y discusión}

Normativas legales sobre acoso escolar: conocimientos obligatorios para los maestros Con la Constitución Política de 1991, Colombia pudo posicionarse como un Estado participativo y democrático, en el que todos los ciudadanos asumieran una función activa frente a las decisiones que toman los gobernantes. Este aspecto de democracia permea a las instituciones Educativas en el 
tema del reconocimiento de la otredad especialmente de los estudiantes, quienes por mucho tiempo estuvieron relegados en todos los procesos de la escuela. Así, recordamos que la democracia es una postura que se contrapone a todas las formas de autocracia (Bobbio, 2007).

Lo anterior está soportado en la Constitución Política cuando señala que es necesario "facilitar la participación de todas las personas en las decisiones que los afectan" y "asegurar la convivencia pacífica" (1991, art. 2). Asimismo, Illera (2005) considera la convivencia ciudadana y convivencia pacífica como parte fundamental de los principios y valores constitucionales. Estas normativas aplicadas a la vida escolar empiezan a mostrarse como brújula de los procesos democráticos, el participar en todos los escenarios que le son propios, el escuchar a los estudiantes y analizar con ellos puntos de vista; $y$, en especial, el trabajo de la empatía como la posibilidad de ponerme en el lugar del otro.

En nuestra Constitución Política (1991) pueden encontrarse también artículos relacionados con la reglamentación de la convivencia y la democracia en un ámbito educativo; algunos de ellos son los artículos 44, 45 y 67. En estos se especifica la obligación que tienen el Estado y los entes educativos frente a la protección de los derechos de los niños, a saber se resaltan algunos que sirven de guía en este aspecto de las normativas: "[...] los niños serán protegidos contra toda forma de abandono, violencia física o moral" (art. 44), "el Estado y la sociedad garantizan la participación activa de los jóvenes en los organismos públicos y privados que tengan a cargo la protección, educación y progreso de la juventud" (art. 45), y "la educación formará al colombiano en el respeto a los derechos humanos, la paz y la democracia"(art. 67). Estos artículos reflejan la imperante necesidad de generar conciencia en los estudiantes sobre la diversidad como elemento de riqueza no de división.

Ahora bien, con la carta magna se dio apertura a leyes que promueven la participación y convivencia en diferentes ámbitos; entre ellos en el contexto escolar a partir de la Ley 115 y el Decreto 1860 de 1994. En estas normativas se propone la importancia de establecer un gobierno escolar mediante el cual se garantice la democracia en los establecimientos educativos como "una forma de preparación para la convivencia democrática, por medio de la participación de todos los estamentos de la comunidad educativa en la organización y funcionamiento del Proyecto Educativo Institucional (PEI)" (MEN, 2016, p. 1). Asimismo, el manual de convivencia es concebido como "una herramienta en la que se consignan los acuerdos de la comunidad educativa para facilitar y garantizar la armonía en la vida diaria" (MEN, 2014, p. 25) de las instituciones educativas. Estos instrumentos deben ser apropiados por todos los actores del ámbito educativo a fin de desarrollar procesos de corresponsabilidad que conlleven a la toma de conciencia sobre el respeto por el otro y lo otro, la empatía, el buen trato y la responsabilidad social.

En el año 2013 fue aprobada la Ley 1620 por la cual se crea el Sistema Nacional de Convivencia Escolar y formación para el ejercicio de los Derechos Humanos, la Educación para la Sexualidad y la Prevención y Mitigación de la Violencia Escolar. Esta ley "se concentra en [el Bullying] y se orienta hacia la mitigación de las violencias y su objeto a la construcción de ciudadanía activa" (Puerta, Builes y Sepúlveda, 2015, p. 19); a partir de esta ley se conforma el Comité Nacional y el Sistema de Información Unificado de Convivencia Escolar, en el que se establecen las rutas y los protocolos de atención integral para situaciones de acoso en las instituciones educativas, además de poner en marcha el programa para el desarrollo de las competencias ciudadanas (Ruiz y Chaux, 2005). Frente al cuestionamiento de cómo sería este sistema, Daza y Vega sostienen:

Un aula en paz es aquella en la que alumnos y profesores reconocen y aprecian las características propias de cada uno, favorecen su desarrollo y autonomía, se tratan con respeto, sienten que se atiende a sus necesidades e intereses, construyen y respetan las normas, manejan de manera constructiva los conflictos, expresan sus emociones, se comunican de manera abierta y efectiva, y cooperan mutuamente para el logro de sus metas. (2004, p. 30)

Incluso, luego de la sanción de la nombrada ley, se han conocido casos de su incumplimiento 
y poco funcionamiento, como lo es la sentencia T-478 de 2015 en la que se presenta una acción de tutela contra una institución educativa de Bogotá, de "discriminación por orientación sexual e identidad de género en ambientes escolares; protección del derecho a la igualdad y del libre desarrollo de la personalidad; corresponsabilidades en el desarrollo educativo de los menores de edad" (2015, p. 1).

A partir de esto, la Corte Constitucional ordenó darle al Ministerio de Educación Nacional (MEN) de Colombia un plazo mínimo de seis meses y máximo de un año para que creara el Sistema Nacional de Convivencia Escolar definitivo; así, como para inspeccionar los manuales de convivencia de todos los colegios del país y diagnosticar su estado según lo promulgado en la normativa; igualmente comprobar que todos los establecimientos educativos tuvieran comités escolares de convivencia; todo lo anterior según la Ley 1620 del 2013 y el Decreto 1965 del 2013 (STC 478/2015 de 3 de agosto).

Además de esta sentencia, se presentaron en el país otros casos de acoso escolar en los que no se hizo una debida intervención y se encontró en algunos manuales de convivencia una transgresión a los derechos humanos. Esto nos permite evidenciar que aunque la ley aborde grandes problemas de nuestra sociedad y nos dé las pautas para combatirlos, no se logra mucho si las organizaciones encargadas de promover y proteger los derechos de niños, niñas y jóvenes (Estado, familia, escuela y sociedad) no la interiorizan ni la llevan a la práctica en los momentos oportunos. Teniendo en cuenta lo anterior, Mockus señala que "para lograr convivencia se hace indispensable el respaldo de tradiciones y/o transformaciones éticas o culturales" (2002, p. 15).

Es así como la escuela es la llamada a transformar las leyes en experiencias significativas con sentido para los sujetos, mediante espacios para la construcción de procesos y deconstrucción de prejuicios que lo único que hacen es dañar vidas y las relaciones entre pares. Con respecto a lo mencionado, es necesario afirmar que la convivencia debe ser "asumida desde su consideración de valor ético, virtud social y deber ser" (Puerta, Builes y Palacio, 2011, p. 144) en tanto es una experiencia que se teje con el otro y para el otro; pues este encuentro lo que posibilita es relacionarse, intercambiar ideas, costumbres, formas de vida que enriquecen el diario vivir.

A raíz de los diferentes escándalos relacionados con el acoso escolar, las instituciones educativas y maestros según Chaux "requieren formación que les permita identificar y diferenciar los diversos tipos de agresión que ocurren en el contexto escolar y contar con herramientas prácticas para prevenir y responder adecuadamente a este tipo de situaciones" (2011, p. 84). Formación que les permitirá adquirir herramientas y estrategias pedagógicas que conlleven al mejoramiento de la convivencia escolar, así como de las competencias para afrontar situaciones de acoso escolar. En esta lógica subrayan Álvarez, Rodríguez, González, Núñez y Álvarez que el conocimiento y dominio de las "técnicas para el manejo del aula, técnicas de resolución de conflictos, legislación ante el incumplimiento de normas y la violencia escolar, organización escolar y detección de los problemas de convivencia" (2010, p. 1), son esenciales no solo para los maestros, sino también para aquellos que se están formando y así contribuir al mejoramiento del ambiente escolar debido a que son un insumo para la construcción de escenarios educativos en paz. Así, se torna menester recordar que "el trabajo de prevención y concientización no tendrá ningún efecto, sí niños y niñas no confían en que el acoso escolar será controlado una vez que lo denuncien" (Schwarz, 2012, p. 51).

En suma, la normativa existente (Ley 1620 de 2013 y Decreto 1965 de 2013) no es suficiente para la mitigación del acoso escolar por sí misma (ninguna normativa por si sola es la solución) si no se cuenta con seres humanos que la interioricen, promuevan y la pongan a funcionar. Asimismo, se necesita de la voluntad de los gobiernos, las instituciones educativas, las familias y la sociedad (Puerta, Builes y Sepúlveda, 2015), es decir, todos los agentes socializadores enfocados en una misma dirección para crear un país que promueva la convivencia, la paz, el diálogo, la participación ciudadana, la equidad, la justicia, el respeto, la responsabilidad social, la empatía, la tolerancia, el pensamiento crítico, la inclusión, el sentido de pertenencia y también el amor. 
La democracia: punto de partida para mejorar los procesos de convivencia en la escuela

En su etimología, la palabra democracia hace referencia al poder que tiene el pueblo sobre el pueblo. Como una breve historia, este término fue creado por los griegos en el siglo $\mathrm{V}$ a. C., a diferencia de otras culturas de la época como los persas, egipcios y chinos; los griegos que participaban de la polis se consideraban entre ellos como iguales y creían que debían tener los mismos derechos y deberes, además de obedecer a las mismas leyes (Savater, 2011). Ahora bien, esto en el contexto de la escuela permite pensar que es necesario generar procesos democráticos, entendidos como el tejido vincular entre seres humanos; tejido que se construye en la cotidianidad del ambiente educativo y que requiere cultivarse a partir del consenso de valores que determinan a los participantes del acto educativo.

La democracia requiere de una participación activa por parte de los sujetos frente a la toma de decisiones y la resolución de conflictos. En este sentido,

164 afirma Pariente "la democracia, como todas las estrategias y modelos, es por su propia esencia un bien cultural, un proceso y un producto, y por lo tanto debe enseñarse como cualquier otro conocimiento" (2003, p. 3). No obstante, según Gallego en ocasiones los procesos democráticos quedan "diluidos en el silencio y en la obediencia ciega y acrítica" (2015, p. 154), porque existe miedo por parte de las instituciones educativas y el colegiado de maestros de que los estudiantes piensen, razonen y decidan; sin embargo "generar hábitos correspondientes a una actitud democrática exige que la escuela misma los haya incorporado" (Beltrán, 2006. p. 7).

Ahora bien, poner en funcionamiento la democracia en las aulas de clase puede aportar al desarrollo y crecimiento personal de los estudiantes y al de toda la comunidad educativa; al tratar los casos de violencia escolar buscando soluciones eficaces, se requiere de justicia, participación de los actores, análisis de cada una de las partes implicadas en los sucesos; además, en este caso, la visión del mediador debe ser fundamentalmente ética y crítica, debido a que son ellos quienes deben orientar a "la comprensión de lo humano, con un pensamiento crítico y una imaginación empática" (García, 2012, p. 182) de tal manera que se logre poner a los unos (los oprimidos/acosados) en los zapatos de los otros (opresores/acosadores).

De esta forma, se puede visibilizar la otredad y la empatía a partir de los procesos de participación y democracia. Ahora bien, en términos pedagógicos, con relación a la construcción de procesos democráticos, es fundamental que se generen espacios de encuentros y desencuentros, en términos académicos, en los que el disenso no sea motivo de pelea y burla sino una oportunidad para enriquecerme con la diferencia. Hoy tenemos en las escuelas más niños, niñas y jóvenes aislados, peleados y acosados porque se ha creído, quizá desde la misma cultura, que aquel que piense, sienta y viva diferente a mí, es un enemigo que se debe atacar. En este sentido, recomienda Arnaiz "Si queremos que las escuelas sean para todos, se hace necesario que los sistemas educativos aseguren que todos los alumnos se sientan cómodos, seguros y protegidos en ella" (1996, p.28).

En este orden de ideas, vale la pena resaltar que los procesos de participación y democracia son temas que le corresponden a la diada familia-escuela; estas dos instituciones deben trabajar unidas y rescatar la democracia como un asunto que se construye y vive con el otro, con los otros. Para ello, es esencial que sean niños, niñas y jóvenes quienes construyan en conjunto las normas que deben cumplirse, además de las sanciones para quienes las incumplan, pues esto potenciará en los educandos niveles de competencias ciudadanas, competencias emocionales, que le permitirán "identificar y responder constructivamente ante las emociones propias y las de los demás" (Chaux, 2004, p.22) y aprenderán a ponderar la igualdad, la equidad, el respeto, "la autonomía y el desarrollo de habilidades de comunicación" (Jaramillo, 2004, p. 74); además, comenzarán a ser más sensatos y responsables con sus actos y decisiones. Al respecto, refieren Flórez y Vivas que "la participación activa y deliberada en la definición de reglas de convivencia de la comunidad escolar y en la determinación de proyectos de aula, contribuyen al desarrollo de su inteligencia y de su autonomía" (2007, p. 171) pero también de asumirse como un sujeto responsable de sus actos y decisiones.

Esto significa, entonces, que en aras de ese ejercicio democrático desde este proyecto de 
investigación se invita a las instituciones educativas a que trabajen mancomunadamente con personeros y líderes en la construcción de propuestas de intervención contra el acoso escolar, pero que también se le apueste a la aceptación de la diferencia y la inclusión, en otras palabras, educar para comprender que el mundo es diverso se convierte en riqueza de la humanidad. Dicha invitación está concebida bajo la premisa que los estudiantes creen y confían más en sus pares; por ello, si se trabaja en prevención del acoso y la violencia escolar con los líderes y estos replican con todo el grupo se tendrán alternativas pensadas desde y para los estudiantes, lo que por antonomasia legitimará las instituciones. Así lo refiere Castillo, que "una condición básica de la democracia moderna es poder contar con instituciones legítimas, es decir, con sentido para los individuos" (2003, p. 38), solo cuando se legitime, no solo la escuela y sus procesos, sino el otro como ser diverso se estará hablando de un cambio en las relaciones humanas, en pos de mejorar la convivencia y lograr un desarrollo ético para que la sociedad promueva la paz, la equidad y la justicia.

Familia y escuela: instituciones responsables de cultivar la convivencia

Colombia es uno de los países que ha tenido uno de los conflictos internos más largos de Latinoamérica, además es una de las naciones con más problemas bélicos en el mundo. Guerra civil, grupos al margen de la ley, corrupción y desigualdades sociales entre otros.

Este conflicto, según el informe ¡Basta ya! Colombia: memorias de guerra y dignidad, confirma que "entre 1958 y 2012 el conflicto armado ha ocasionado la muerte de por lo menos 220.000 personas" (Grupo Memoria Histórica, 2013, p. 20); cifras que reflejan la realidad del territorio colombiano y quiérase o no afecta a la familia, la escuela y la sociedad.

En coherencia con lo dicho, es oportuno aclarar que el concepto de violencia es definido por la Organización Panamericana de la Salud como el "uso intencional de la fuerza, el poder físico o amenaza en contra de uno mismo, otra persona o una comunidad, que cause o tenga muchas probabilidades de producir lesiones, muerte, daños psicológicos, trastornos del desarrollo o privaciones"
(2002, p. 5). Para Jimeno es "una forma particular de interacción entre personas y grupos humanos en un contexto ambiental específico, determinada por la intención de hacer daño a otros" (1998, p. 89). Lo que significa entonces, que el concepto de violencia remite necesariamente a la expresión de sentimientos negativos que generalmente dañan a sí mismo o a otros sujetos. Esta no regulación de sentimientos, traducidos como violencia o violencias, impacta la familia, la escuela y la sociedad. Con respecto a lo dicho, García resalta que "las expresiones de violencia se deben considerar en los escenarios de socialización familiar, escolar y barrial, puesto que es allí donde se producen las relaciones que en algunos casos se manifiestan a través de formas violentas" (2008, p. 109).

Del mismo modo, lanni afirma que "lo que se habla en cada escuela, es el lenguaje particular de la sociedad. Por tal motivo, no es ajena a la profunda crisis socio política en la que estamos inmersos y que como ciudadanos nos afecta" (2003, p. 2). De acuerdo con lo afirmado, la escuela no debe estar descontextualizada frente a las problemáticas del país, ya que estas, según Caballero "son en gran medida, fiel reflejo de nuestras sociedades" (2007, p. 1) es por esta razón que en los establecimientos educativos se deben abordar los conflictos desde el diálogo, la tolerancia y el respeto a los derechos humanos, con el fin de brindarles a los estudiantes herramientas tales como:

Los aprendizajes para la gestión de conflictos, el diálogo de saberes y la negociación cultural, la toma de decisiones conjuntas o llegar a acuerdos, colaborarse mutuamente y aprender a participar de manera organizada en el direccionamiento de la misión escolar, en un horizonte de inclusión. (Alcaldía Mayor de Bogotá, 2013, p. 25)

Las herramientas nombradas en las líneas anteriores son un insumo significativo para las instituciones educativas en lo referido a la re-solución de situaciones problemáticas en el día a día del ambiente escolar: es la diada escuela y familia la invitada a resignificar los canales de comunicación y de solución de problemas porque en la misma cotidianidad se encuentra que cuando al hijo de " $\mathrm{A}$ " 
le pega un compañero, el papá de "B" le dice "no te dejes pegar, pégale tú también".

El ejemplo referido ilustra la importancia de generar cultura en las familias; cultura que conlleve a una convivencia pacífica; entendida en palabras de Bello (2014, p. 322) "un conjunto de normas de conducta, reglas y códigos establecidos que permiten a las personas convivir en armonía". Para Ortega, por ejemplo, es "la esencia que vincula a los individuos y que les hace vivir, armónicamente, en grupo" (2007, p. 50). Yánez y Galaz la definen como "la capacidad de las personas de vivir con otras en un marco de respeto mutuo y solidaridad recíproca" (2011, p. 14). Vemos, entonces, que los tres autores puntualizan, con relación a la convivencia, en palabras como armonía, convivir y solidaridad; palabras que recogen la esencia del buen vivir; dicha esencia se refleja en la mediación, el diálogo y la generación de soluciones justas y equitativas. En esta línea, señala Pérez que la convivencia:

Más allá de adquirir ciertos saberes sobre la regulación de la convivencia entre los seres humanos [...] es posible aprender a practicar los derechos y deberes de la ciudadanía y, todavía más importante, a convivir en el respeto y la tolerancia a todas las personas, incluidas aquellas que tienen formas diferentes de pensar, valores distintos que respetar, modelos de vida distantes de los propios. (2007, p. 250)

No se puede negar que en la cotidianidad de la escuela se hacen evidentes la diversidad de conflictos, expresados en argumentos como "me miró feo", "no me miró", "no se parece a mí", "quiere sobresalir porque participa mucho en clase", "se cree sabelotodo", etc. Estos ejemplos lo que reflejan son cierto grado de inmadurez por parte de los estudiantes y que ocasionan fracturas en la tolerancia. Ellos desde su poca experiencia juzgan al otro como un enemigo y es ahí donde se empieza a complejizar la dinámica escolar haciendo de estos espacios ambientes hostiles para el que se denominaría "el más débil".

Frente a expresiones como las nombradas en las líneas anteriores es que los agentes educativos deben estar atentos para intervenir desde posiciones pedagógicas acciones como tratar de poner al niño, niña o adolescente en el lugar del otro. Este ponerse en el lugar del otro generará nuevas dinámicas que se reflejaran en la tolerancia, el respeto al otro y el diálogo; y lo que evitará por antonomasia que ese conflicto se transforme en un factor que promueve la transgresión de la norma, la violación a los derechos humanos y por supuesto el acoso escolar.

Por ello, es importante que la convivencia en la escuela sea una práctica diaria, que se aproveche cada actividad de clase para generar casos de la vida cotidiana en el que los estudiantes no solo desarrollen procesos cognitivos sino también reflexiones sobre sus propias actitudes, comportamientos y acciones; que identifiquen y reconozcan las conductas que vulneran los derechos del prójimo y perjudiquen el bienestar en el aula. En este sentido Agudelo y Gallego (2016), afirman que:

Sí se trabaja desde el binomio familia-escuela, en pro de una apuesta formativa que logre fortalecer las competencias ciudadanas, se estará garantizando un educando con habilidades para la convivencia pacífica; así como el cultivo de conocer y practicar valores tales como la libertad, la tolerancia, el respeto, la solidaridad y la igualdad en el aula. (p.15)

En este punto, también es importante señalar que los ambientes democráticos (MEN, 2004) que genere tanto maestro como cuidador son esenciales no solo para el aprendizaje, sino también para tejer relaciones basadas en la sana convivencia; y así lo señala Díaz "cuando las relaciones son adecuadas representan una importante fuente de apoyo y motivación para el aprendizaje. Cuando, por el contrario, las relaciones son inadecuadas, se convierten en una fuente de estrés e inhiben la actividad necesaria para aprender" (2002, p. 14). De igual manera, Milicic y Arón afirman "los factores que se relacionan con un clima social positivo son: un ambiente físico apropiado, actividades variadas y entretenidas, comunicación respetuosa entre profesores y alumnos, y entre compañeros, capacidad de escucharse unos a otros, capacidad de valorarse

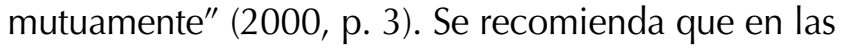
IE favorezcan la convivencia porque esta se verá reflejada en un adecuado clima escolar, y los estudiantes tendrán más confianza a la hora de manifestar sus experiencias, concepciones y sentimientos. 
Es importante, entonces, que desde las mismas direcciones de las IE se revise la dinámica escolar, es decir, que la escuela recupere su lugar en términos de saber y se afiancen las relaciones en la concepción de horizontalidad. Aspecto que resalta Martínez al subrayar que tener en cuenta a los estudiantes "supone cambiar las relaciones jerárquicas, los profesores vencen sus miedos y límites y abordan sus relaciones conflictivas con los alumnos, quienes necesitan destrezas y familiaridad en el entorno de comunicación con una buena relación con el profesor" (2010, p. 170).

\section{Conclusiones}

La normativa de la convivencia escolar y la democracia permite que Colombia se posicione como un país que se proyecta como participativo y constructor de paz; regido por leyes antiviolencia que facilitan la intervención de los diferentes tipos de violencia que se presente en los establecimientos educativos. Sin embargo, sabemos que ninguna normativa por sí sola funciona; para que estas se concreten se requiere de las voluntades humanas y que mejor que la articulación familia-escuela, como canales para que estas normativas dejen de ser exclusivamente jurídicas y pasen a ser quehaceres culturales y acciones cotidianas de respeto, escucha y tolerancia como posibilidad de aprendizaje e intercambio cultural.

La formación en valores, la participación en cada escenario, el respeto a las normas y a la diversidad, además de las políticas públicas y planes, son acciones que promueven y fomentan la convivencia no solo en las IE, sino también en la sociedad colombiana. En este sentido, refiere Ospina señala que “... el propósito de todo proceso educativo no es sólo crear seres humanos libres, lúcidos, armoniosos y expresivos, sino seres con un sentimiento profundo de pertenencia a una comunidad" (s.f., p. 10) con capacidades y competencias para tomar decisiones y hacerse responsables de sus actos. Seres humanos encarnados en la figura de estudiante, con el valor de comprometerse con los procesos de formación que no solo implican el cúmulo de conocimientos o la respuesta a áreas del saber, sino de asumir con responsabilidad los derechos y deberes como punto central en la promulgación de la existencia.
El arraigo de la convivencia no solo es un trabajo y compromiso de la escuela, sino una labor mancomunada entre escuela-familia en tanto estos escenarios tienen como responsabilidad formar en valores para asumirse dentro de una sociedad. Es por ello por lo que la misma sociedad reclama a gritos "el diálogo entre ambas instituciones para buscar puntos de convergencia, a la vez que delimitar competencias y buscar cauces de interrelación que permitan una comunicación fluida, una información bidireccional y una colaboración de los padres en el contexto educativo" (Torío, 2004, p. 35), solo así podríamos hablar de una trasformación social en la que los seres humanos desarrollen competencias para resolver las diferencias por vías distintas a comportamientos agresivos.

Lo anterior sugiere que a partir de mecanismos de participación, la convivencia y el clima escolar arrojaran como resultado un ciudadano participativo, activo y autónomo. No obstante, los agentes educativos no se deben supeditar solo al espacio escolar, este debe trascender e impactar la sociedad, es decir "la institución educativa contemporánea requiere abrir espacios sociales incluyentes como alternativa que permita entablar una nueva relación dialógica con padres y madres de familia y con su entorno barrial más próximo" (García, 2008, p. 121).

Por lo anterior, es sumamente importante el ejemplo que brinden los maestros, directivos y padres a los niños, pues si estos ven que solucionan sus problemas pacíficamente y están en pro de una relación bidireccional, además de que practican la empatía y el respeto hacia la diferencia, los niños y adolescentes tendrán un referente positivo frente a la solución de conflictos. Esto da pie para un libre desenvolvimiento de la personalidad, además de la formación integral del sujeto, también comprenderá la importancia de aplicar este clima positivo que fue construido por todos sus compañeros, maestro(s) y padres en otros escenarios sociales.

Estas acciones interiorizadas por todos los agentes del acto educativo y vivenciadas en los escenarios de socialización favorecerán la formación para la paz y la convivencia, disminuyendo, o mejor, erradicando la intolerancia que en ocasiones es traducida, en el contexto escolar, como el bullying o acoso escolar. 
Finalmente, y desde el contexto escolar, el maestro no solo debe estar preparado para labores académicas sino también para hacerle frente a las dificultades en la convivencia que ocurran durante la jornada, es por esta razón que son los maestros los Ilamados a reconocer la convivencia escolar y a la democracia como uno de los factores más importantes frente a la prevención y mitigación de la violencia, de manera que permitan la construcción de paz, tolerancia, equidad y de ambientes pacíficos.

\section{Referencias}

Agudelo, J. F. y Gallego, A. M. (2017). Repensar el acoso escolar desde el desarrollo humano: una oportunidad para los profesionales de la educación. Revista Espacios, 38(45), 13-27. Recuperado de http://www.revistaespacios. com/a17v38n45/17384513.html y https://doi. org/10.21501/23823410.2169

Alcaldía Mayor de Bogotá, Secretaría de Educación del Distrito (2013). Educación para la ciudadanía y la convivencia. Bogotá: Equipo editorial.

Álvarez, D., Rodríguez, C., González, P., Núñez, J. C. y Álvarez, L. (2010). La formación de los futuros docentes frente a la violencia escolar. Revista de Psicodidáctica, 15(1), 35-56.

Arellano, N. (2008). Violencia entre pares escolares (bullying) y su abordaje a través de la mediación escolar y los sistemas de convivencia. Informe de Investigaciones Educativas, XXII(2), 211-230.

Arellano, N., Chirinos, Y., López Z. y Sánchez, L. (2007). Los tipos de maltrato entre iguales. Quaderns Digitals, 1-18. Recuperado de http:// www.quadernsdigitals.net/datos/hemeroteca/r_1/nr_772/a_10404/10404.html

Arnaiz, P. (1996). Las escuelas son para todos. Siglo Cero: Revista Española sobre Discapacidad Intelectual, 27(2), 25-34. Recuperado de http:// www.inclusioneducativa.org/content/documents/Escuelas_Para_Todos.pdf

Avilés, J. (2002). La intimidación y el maltrato en los centros escolares (bullying). Lan Osasuna, 2, 1-13. Recuperado de http://www. deciencias.net/convivir/1.documentacion/D. maltrato.acoso/Intimidacion_maltrato(JM.Aviles-2002)13p.pdf
Bello, C. (2014). Desafíos y estado futuro de la convivencia en Colombia al 2025. Criminalidad, 56(2), 319-332. Recuperado de https://policia. gov.co/sites/default/files/56209.html

Beltrán, F. (2006). La democracia escolar: lugares y efectos del poder en las Instituciones Educativas y su gestión. Ponencia en XVII Jornadas Estatales: Democracia, Ciudadanía y Ética de las Organizaciones. Recuperado de https:// docs.google.com/document/d/1 xwHp9zZbvAEq3faqRtJlp4hmeH5XnYtfsuKs6GX97Vk/ edit

Bobbio, N (2007). Pensar la democracia. México D. F.: Universidad Autónoma de México.

Caballero, A. (2007). La escuela en conflicto como escenario de socialización. Rescoldos: Revista de Diálogo Social, 16, 7-16.

Castillo, E. (2003). Democracia y ciudadanía en la escuela colombiana. Acción Pedagógica, 12(1), 32-39. Recuperado de http://www.saber.ula. ve/bitstream/handle/123456789/17091/articulo_4.pdf? sequence $=2$

Cerezo, F. (2012). Psique: Bullying a través de las TIC. Boletín Científico Sapiens Research, 2(2), 24-29. Recuperado de https://www.srg.com.co/ bcsr/index.php/bcsr/article/view/61/53

Chaux, E. (2004). Aproximación integral a la formación ciudadana. En E. Chaux, J. Lleras y A. Velásquez (comp.), Competencias ciudadanas: de los estándares al aula. Una propuesta integral para todas las áreas académicas (pp. 13-25). Bogotá: Uniandes. https://doi. org/10.7440/2004.01

Chaux, E. (2011). Múltiples perspectivas sobre un problema complejo: comentarios sobre cinco investigaciones en violencia escolar. Psykhe, 20(2), 79-86. Recuperado de http://www.psykhe.cl/index.php/psykhe/article/view/00007/7 https://doi.org/10.4067/ s0718-22282011000200007

Collel, J. y Escudé, C. (2002). La violencia entre iguales en la escuela: el bullying. Àmbits de Psicopedagogía, 4, 20-24.

Congreso de la República de Colombia (1994). Ley general de Educación [Ley 115]. Bogotá: Congreso de Colombia.

Congreso de la República de Colombia (2013). Ley 1620. Bogotá: Congreso de Colombia. 
Constitución Política de la República de Colombia (1991). Asamblea Nacional Constituyente, Bogotá: Presidencia de la Republica.

Corte Constitucional de la República de Colombia (2015). Sentencia T 478. Bogotá: Corte Constitucional. Recuperado de http://www.corteconstitucional.gov.co/inicio/T-478-15\%20 ExpT4734501\%20(Sergio\%20Urrego).pdf

Daza, B. y Vega, L. (2004). Aulas en Paz. En E. Chaux, J. Lleras y A. Velásquez (comp.), Competencias ciudadanas: de los estándares al aula. Una propuesta de integración a las áreas académicas (pp. 29-40). Bogotá: Uniandes.

Díaz, M. (2002). Convivencia escolar y prevención de la violencia. Instituto Nacional de Tecnologías Educativas y de formación del profesorado. Madrid: Ministerio de Educación, Cultura y Deporte. Recuperado de http://www.aulaviolenciadegeneroenlocal.es/consejosescolares/ archivos/Convivencia_escolar_y_prevencion_ de_violencia.pdf

Domínguez, F. y Manzo, M. (2011). Las manifestaciones del bullying en adolescentes. Uaricha: Revista de Psicología, 8(17), 19-33. Recuperado de https://www.academia.edu/11260125/Manifestaciones_del_Bullying_en_adolescentes

Flórez, R. y Vivas, M. (2007). La formación como principio y fin de la acción pedagógica. Educación y Pedagogía, XIX (47), 165-173. Recuperado de http://aprendeenlinea.udea. edu.co/revistas/index.php/revistaeyp/article/ view/6680/6122

Gallego, A. (2011). La agresividad infantil: una propuesta de intervención y prevención pedagógica desde la escuela. Revista Virtual Universidad Católica del Norte, 1(33), 295-314. Recuperado de http://revistavirtual.ucn.edu.co/index. php/RevistaUCN/article/viewFile/6/12

Gallego, A. (2015). Participación infantil... Historia de una relación de invisibilidad. Revista Latinoamericana de Ciencias Sociales, Niñez y Juventud, 13(1), 151-165. Recuperado de http://revistaumanizales.cinde.org.co/rlcsnj/ index.php/Revista-Latinoamericana/article/ view/1642/539

García, B. (2008). Familia, escuela y barrio: un contexto para la comprensión de la violencia escolar. Revista Colombiana de Educación, 55, 108124. https://doi.org/10.17227/01203916.7573
García, D. E. (2012). Martha Craven Nussbaum. Sin fines de lucro. Por qué la democracia necesita de las humanidades. Enfoques, X(16), 181-185.

Grupo Memoria Histórica (2013). ¡Basta ya! Colombia: memorias de guerra y dignidad. Bogotá: Imprenta Nacional. https://doi.org/10.15446/ hys.n26.44516

lanni, N. (2003). La convivencia escolar: una tarea necesaria, posible y compleja. Revista Iberoamericana, 2, 1-4. Recuperado de http:// www.oei.es/historico/valores2/monografias/ monografia02/reflexion02.htm

Illera, M. (2005). Convivencia y cultura ciudadana: dos pilares fundamentales del Derecho policivo. Revista de Derecho, 23, 240-259.

Jaramillo, P. (2004). Proyectos. En E. Chaux, J. Lleras y A. Velásquez (comp.), Competencias ciudadanas: de los estándares al aula. Una propuesta integral para todas las áreas académicas (pp. 69-74). Bogotá: Uniandes. https://doi. org/10.7440/2004.01

Jimeno, M. (1998). Corrección y respeto, amor y miedo en las experiencias de violencia. En J. Arocha, F. Cubides y M. Jimeno (eds.), Las violencias: inclusión creciente (pp. 87-102). Bogotá: Universidad Nacional de Colombia.

Martínez, J. (2010). El currículo como espacio de participación. La democracia escolar ¿es posible? En J. Sacristán (comp.), Saberes e incertidumbres sobre el currículo (pp. 161-179). Valencia, España: Morata.

Milicic, N. y Arón, A. (2000). Climas sociales tóxicos y climas sociales nutritivos para el desarrollo personal en el contexto escolar. Psykhe, 9(2), 117-123.

Ministerio de Educación Nacional (1994). Decreto 1860. Recuperado de https://www. mineducacion.gov.co/1621/articles-86240_ archivo_pdf.pdf

Ministerio de Educación Nacional (2004). Formar para la ciudadanía... iSí es posible! Bogotá: Ministerio de Educación Nacional. Recuperado de https://www.mineducacion.gov.co/1621/ articles-116042_archivo_pdf4.pdf

Ministerio de Educación Nacional (2013). Decreto 1965. Recuperado de http://www. mineducacion.gov.co/1621/articles-328630_ archivo_pdf_Decreto_1965.pdf 
Ministerio de Educación Nacional (2014). Manual de convivencia. Guías pedagógicas para la convivencia escolar. Bogotá: Ministerio de Educación Nacional. Recuperado de http:// redes.colombiaaprende.edu.co/ntg/men/pdf/ Guia\%20No.\%2049.pdf

Ministerio de Educación Nacional (2016). Proyecto Educativo Institucional. ¿Qué es el Gobierno Escolar? Observatorio de Medios. Bogotá: Ministerio de Educación Nacional.

Mockus, A. (2002). La educación para aprender a vivir juntos: convivencia como armonización de ley, moral y cultura. Perspectivas, XXXII(1), 19-37.

Olweus, D. (1993). Acoso escolar, "bullying", en las escuelas: hechos e intervenciones. Centro de Investigación para la Promoción de la Salud, Universidad de Bergen, Noruega. Recuperado de https://www.researchgate.net/ publication/253157856_ACOSO_ESCOLARBULLYING_EN_LAS_ESCUELAS_HECHOS_E_ INTERVENCIONES

Organización Panamericana de la Salud (2002). Informe mundial sobre la violencia y la salud: resumen. Washington: Organización Panamericana de la Salud.

Ortega, R. (2007). La convivencia: un regalo de la cultura a la escuela. Idea La Mancha: Revista de Educación de Castilla-La Mancha, 4, 50-54.

Ospina, W. (s. f.). Carta al maestro desconocido.

Pariente, J. (2003). Educar para la democracia: algunas contradicciones internas del sistema educativo mexicano. Ponencia presentada en I Foro Internacional de Participación
Social. Recuperado de https://www.academia. edu/802665/Educar_para_la_democracia

Pérez, R. (2007). Educación, ciudadanía y convivencia. Diversidad y sentido social de la educación. Bordón: Revista de Pedagogía, 59(2-3), 239-260.

Puerta, I., Builes, L. y Palacio, M. (2011). Convivencia escolar. En I. Puerta y L. Builes (eds.), Abriendo espacios flexibles en la escuela (pp. 143-154). Medellín: Universidad de Antioquia.

Puerta, I., Builes, L. y Sepúlveda, M. (2015). Convivir pazcíficamente: oportunidades que ofrece la Ley 1620. Medellín: Universidad de Antioquia.

Ruiz, A. y Chaux, E. (2005). La formación de competencias ciudadanas. Bogotá: Ascofade.

Savater, F. (1993). Política para Amador. Barcelona, España: Ariel.

Schwarz. A. (2012). El libro del bullying: bullying, cyberbullying y sexting, un peligro mayor. Madrid: Ediciones Pirámide.

Torío, S. (2004). Familia, escuela y sociedad. Aula Abierta, 83, 35-52.

Trautmann, A. (2008). Maltrato entre pares o buIlying. Una visión actual. Revista Chilena de Pediatría, 79(1), 13-20. Recuperado de https:// scielo.conicyt.cl/scielo.php?script=sci_arttext\&pid=S0370-41062008000100002 https://doi. org/10.4067/s0370-41062008000100002

Yánez, P. y Galaz, J. (2011). Conviviendo mejor en la escuela y en el liceo: orientaciones para abordar la Convivencia Escolar en las Comunidades Educativas. Santiago de Chile: Ministerio de Educación, República de Chile.

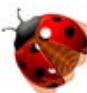

\section{(C) (1)(}

Esta obra está bajo licencia Creative Commons Atribución-NoComercial-Compartirlgual 4.0 Internacional https://creativecommons.org/licenses/by-nc-sa/4.0/deed.es

ISSN 1657-9089 • Vol 18, No 2 (julio-diciembre 2019). pp. 159-170 